Research Article

\title{
Genetic variability in mitochondrial and nuclear genes of Larus dominicanus (Charadriiformes, Laridae) from the Brazilian coast
}

Gisele Pires de Mendonça Dantas ${ }^{1}$, Diogo Meyer $^{1}$, Raquel Godinho ${ }^{2}$, Nuno Ferrand ${ }^{2}$ and João Stenghel Morgante ${ }^{1}$

${ }^{1}$ Laboratório de Biologia Evolutiva e Conservação de Vertebrados, Departamento de Genética e Biologia Evolutiva, Instituto de Biociências, Universidade de São Paulo, São Paulo, SP, Brazil. ${ }^{2}$ Centro de Investigação em Biodiversidade e Recursos Naturais, Porto, Portugal.

\begin{abstract}
Several phylogeographic studies of seabirds have documented low genetic diversity that has been attributed to bottleneck events or individual capacity for dispersal. Few studies have been done in seabirds on the Brazilian coast and all have shown low genetic differentiation on a wide geographic scale. The Kelp Gull is a common species with a wide distribution in the Southern Hemisphere. In this study, we used mitochondrial and nuclear markers to examine the genetic variability of Kelp Gull populations on the Brazilian coast and compared this variability with that of sub-Antarctic island populations of this species. Kelp Gulls showed extremely low genetic variability for mitochondrial markers (cytb and ATPase) and high diversity for a nuclear locus (intron 7 of the $\beta$-fibrinogen). The intraspecific evolutionary history of Kelp Gulls showed that the variability found in intron 7 of the $\beta$-fibrinogen gene was compatible with the variability expected under neutral evolution but suggested an increase in population size during the last 10,000 years. However, none of the markers revealed evidence of a bottleneck population. These findings indicate that the recent origin of Kelp Gulls is the main explanation for their nuclear diversity, although selective pressure on the mtDNA of this species cannot be discarded.
\end{abstract}

Key words: cytb, FIB7 intron, phylogeography, recent origin, selective sweep.

Received: January 13, 2012; Accepted: June 28, 2012.

\section{Introduction}

The gull genus Larus, which consists of 25 species worldwide, has a complex evolutionary history. Twentyone species of Larus occur in the Northern Hemisphere and hybridization among several species in areas of secondary contact has been documented (Liebers et al., 2001; Crochet et al., 2003; Pons et al., 2004). Most studies of the genus Larus have addressed the systematics of this group and have reported recent divergence among various species (Crochet et al., 2003; Pons et al., 2005). Some studies have concluded that the last glaciations had a strong influence on the evolutionary pressures acting on this group (Liebers et al., 2001, 2004; Crochet et al., 2003). In contrast to Northern Hemisphere species, little is known about the four species of Larus that occur in the Southern Hemisphere. Indeed, the work described in here is the first study to examine the population genetics of this group.

Send correspondence to Gisele P.M. Dantas. Laboratório de Biodiversidade e Evolução Molecular, Instituto de Ciências Biomédicas, Universidade Federal de Minas Gerais, Av. Antonio Carlos 6627, Sala L3-244, 31270-010 Belo Horizonte, MG, Brazil. E-mail: giselebio@yahoo.com.br.
Larus dominicanus (Kelp Gull) (Charadriiformes: Laridae) is a common species that is widely distributed in the Southern Hemisphere, including South America, southern Africa, Australia, New Zealand, sub-Antarctic islands and the Antarctic Peninsula (Burguer and Gochfeld, 1996). Several studies have documented a large increase in the size of Kelp Gull populations in recent decades (Quintana and Yorio, 1998; Steele and Hockey, 1990). For example, the Kelp Gull population of the Valdez Peninsula, Argentina, reportedly increased from 3,200 to 6,500 breeding pairs in 10 years (Quintana and Yorio, 1998). These increases in population size may reflect the fact that the Kelp Gull is a competitive species that preys on several seabird species and displaces many species from their breeding sites (Quintana and Yorio, 1998). However, the effects of Kelp Gulls on coastal wildlife are not confined to other seabirds. Thomas (1988) and Rowntree et al. (1998) observed Kelp Gulls injuring Right Whales (Eubalaena australis) by picking off skin and fat when the whales surfaced to breathe. These authors argued that intense harassment by gulls caused Right Whales to abandon breeding areas before their young are sufficiently strong for the open sea. 
For several species of seabirds, there are few or no vicariant processes and extrinsic barriers to dispersion (Congdon et al., 2000), leading to the expectation that low levels of population structure should be observed. On the other hand, strong philopatry, a wide geographic distribution or historic separation can create substantial genetic differentiation in some species (Genovart et al., 2003). Several studies had shown low population structure in seabirds (Austin et al., 1994; Friesen et al., 1996). On the Brazilian coast, the few studies that have been done have shown low genetic differentiation on a wide geographic scale. Faria et al. (2010) observed low genetic structure in the South American Tern (Sterna hirundinacea) on the Brazilian coast. Gonçalves et al. (2007) also found low genetic structure in Calidris pusilla on the north coast of Brazil. A similar pattern was observed for Sula dactylacta and Sula leucogaster along the Brazilian coast (Baumgarten MM, 2003, PhD thesis, Universidade de São Paulo, São Paulo, Brazil). In all three cases, low genetic differentiation was attributed to a high capacity for dispersion that homogenized the genetic variability among population or to a population bottleneck that reduced the genetic diversity through the loss of a large number of individuals.

For many years, phylogeographic studies were based on the analysis of a single locus for mitochondrial markers (Austin et al., 1994; Brown et al., 2004; Helbig and Seibold, 1999; Avise et al., 2000). However, more recently, the use of nuclear markers to infer evolutionary history has proven to be highly informative; these markers allow inferences on more remote demographic events that have helped to clarify the evolutionary history of many groups (Hare et al., 2002; Godinho et al., 2006; Melo-Ferreira et al., 2009). Mitochondrial and nuclear markers have different effective population sizes and modes of inheritance such that demographic events shape the variation in these genetic markers in distinct ways (Zink and Barrowclough, 2008). In addition, because mitochondria do not generally undergo recombination any selection events on a mitochondrial gene would tend to decrease the diversity at linked loci through hitch-hiking or background selection (Bazin et al., 2006). Since mitochondria show maternal inheritance the pattern observed for this molecule faithfully represents the history of the population based on female patterns (Ballard and Whitlock, 2004). In contrast, nuclear markers reflect both male and female histories (Zhang and Hewitt, 2003), have deeper coalescence times and experience recombination, thus making distinct unlinked markers independent. Consequently, studies that use both markers should provide a more accurate evolutionary history of the group being investigated.

Into this context, Kelp Gulls are an interesting group in which to study phylogeography patterns because of their wide distribution, fast-growing populations and intense interaction with other species. The use of nuclear and mitochondrial markers should allow us to reconstruct the evolu- tionary history of this species on the Brazilian coast. The aim of the present study was to estimate the divergence of the Kelp Gull from its sister groups and to describe the genetic variability of this species in populations on the Brazilian coast in comparison with sub-Antarctic islands populations of this species. Two major questions were addressed: 1) Are Brazilian populations genetically different from each other and from non-Brazilian populations? and 2) Is there genetic evidence for a population bottleneck or expansion in the recent evolutionary history of Kelp Gulls?

\section{Materials and Methods}

\section{Phylogenetic analysis}

The phylogenetic analyses of the Larus group reported by Liebers et al. (2004) and Pons et al. (2005) located the Kelp Gull in a group consisting of large whiteheaded gulls. Based on these analyses, we sought to estimate the divergence of the Kelp Gull from its sister groups. For this, we used 105 specimens, i.e., five specimens of $L$. dominicanus and 98 individuals from other taxa of the genus Larus; the phylogeny was rooted with the two individuals from genus Rissa with 405 bp of cytochrome b, obtained from GenBank (Supplementary material Table S1). The sequences were aligned by eye using Bioedit v. 7.0 (Hall, 2001). The most appropriate model of DNA evolution for the sequences was inferred with MODELTEST (Posada and Cradall, 1998) implemented in PAUP v. 4.0 (Swofford, 2000). Bayesian inferences were done using BEAST v.1.4.8 software (Drummond and Rambaut, 2007). This analysis was based on the following assumptions: a restricted molecular clock, a $2 \%$ per million years substitution rate and a 3.3 Mya (Million years ago) divergence between the genera Rissa and Larus (Paton et al., 2003). We then used a portioned Bayesian Inference search in a Markov-Chain Monte Carlo analysis to run four independent chains, each with 10,000,000 steps and sampled every 1000 steps, excluding a burn-in of $1,000,000$ trees. The parameter analysis was visualized by means of Tracer v. 1.4.1 software and the trees were connected in TreeAnotator and visualized in FigTree (Drummond and Rambaut, 2007).

\section{Intraspecific analysis}

\section{Population sampling}

This study was based on samples from seven islands on the Brazilian coast and two sub-Antarctic islands (Figure 1). Individuals were captured using a hand net and marked with a metal ring provided by CEMAVE/IBAMA (license no. 1060) during the breeding seasons from 2002 to 2005. Blood samples were collected from the brachial vein of all captured individuals and stored in $100 \%$ ethanol at room temperature. This blood collection technique did not injure the gulls or result in any deaths. The samples were stored in the Laboratório de Biologia Evolutiva e Conservação de Vertebrados (LABEC/IB-USP). Total genomic 


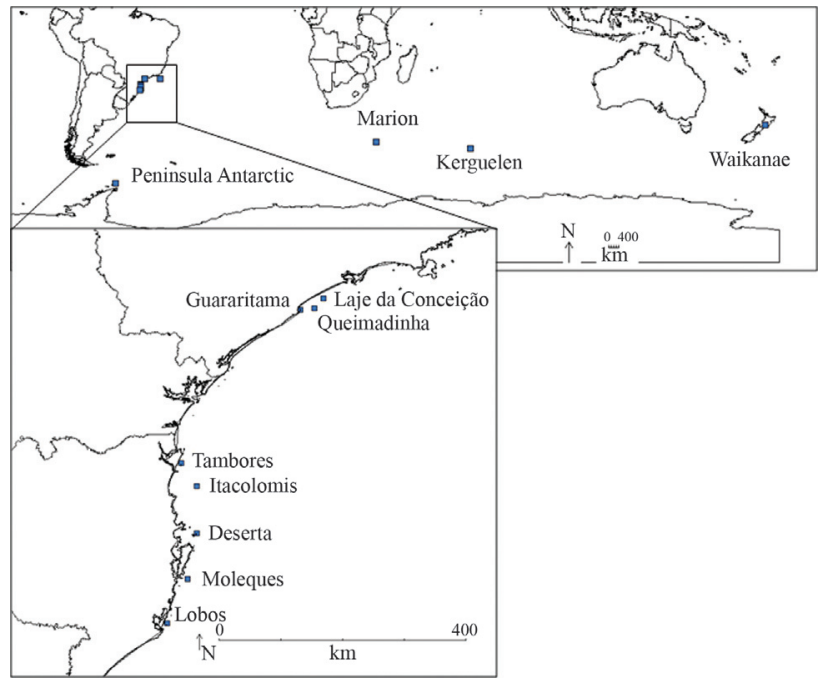

Figure 1 - Locations of the breeding colonies of $L$. dominicanus sampled in the Southern Hemisphere: São Paulo (Laje Conceição, Guararitama and Queimadinha), Santa Catarina (Tambores, Itacolomis, Deserta, Moleques and Lobos), Antarctic Peninsula, Marion Island and Kerguelen Island.

DNA was isolated from blood samples by a standard phenol/chloroform technique, precipitated with ethanol and resuspended in Tris-EDTA (TE) buffer (Sambrook et al., 2001). In addition, sequences available in GenBank from Kerguelen Island and New Zealand were included in the analysis to compare genetic diversity.

\section{Molecular methods}

Two regions of mitochondrial DNA (ATPase 8 and 6 of $\sim 750 \mathrm{bp}$ and cytochrome $b(c y t b)$ of $\sim 350 \mathrm{bp}$ ) and one nuclear (intron 7 of $\beta$-fibrinogen, $\sim 900 \mathrm{bp}$ ) were used in this study. ATPase 8 is the second most variable region of the mitochondrial genome in birds, but it is short (165-168 pb). The $c y t b$ gene is a well-conserved region with an estimated substitution rate of $2 \% / \mathrm{Myr}$ for the entire avian mitochondrial genome (Shields and Wilson, 1987; Bridge et al., 2005 ). Intron 7 of $\beta$-fibrinogen is located on chromosome 4 in chicken (Gallus gallus) and has been used in other phylogeographic studies (Bridge et al., 2005; Godinho et al., 2006; Gonçalves et al., 2007); this intron has an evolutionary rate of $0.53 \% / \mathrm{Myr}$ in the pigeon (Johnson and Clayton, 2000). The ATPase 8 and 6 fragments were amplified using primers Lys (Sorenson et al., 1999) and int-H (Faria et al., 2007), cytb was amplified using primers $L 15008$ and H1532b (Desjardin and Morais, 1990) and intron 7 of $\beta$-fibrinogen was amplified using primers FIB7U and Fib7L (Prychitko and Moore, 2000). The reactions for ATPase 8 and 6 and cytb were run in a final volume of 10 $\mu \mathrm{L}$ containing $1 \mathrm{X}$ Taq platinum polymerase buffer $(10 \mathrm{mM}$ Tris-HCl, $\mathrm{pH} 8.3,50 \mathrm{mM} \mathrm{KCl}), 2.5 \mathrm{mM} \mathrm{MgCl}_{2}, 2 \mathrm{mM}$ of each dNTP, 10 pmol of primer, 0.5 units of Taq polymerase and approximately $20 \mathrm{ng}$ of DNA. The PCR cycling sequence consisted of $94^{\circ} \mathrm{C}$ for $5 \mathrm{~min}$, followed by 35 cycles of $94{ }^{\circ} \mathrm{C}$ for $45 \mathrm{~s}, 58{ }^{\circ} \mathrm{C}$ for $35 \mathrm{~s}$ and $72{ }^{\circ} \mathrm{C}$ for $45 \mathrm{~s}$, with a fi- nal extension at $72{ }^{\circ} \mathrm{C}$ for $10 \mathrm{~min}$. The PCR for $\beta$-fibrinogen PCR was done in a final volume of $10 \mu \mathrm{L}$ containing 1X PCR buffer (50 mM Tris- $\mathrm{HCl}, 50 \mathrm{mM} \mathrm{NaCl}, \mathrm{pH} 8.5$ ), $200 \mathrm{uM}$ of each dNTP, 0.5 units of GoTaq DNA polymerase (Promega), 5 pmol of each primer and approximately $50 \mathrm{ng}$ of DNA. The PCR began with an initial denaturation of $5 \mathrm{~min}$ at $95^{\circ} \mathrm{C}$ followed by 38 cycles of $30 \mathrm{~s}$ at $95^{\circ} \mathrm{C}, 45 \mathrm{~s}$ at $60{ }^{\circ} \mathrm{C}, 1 \mathrm{~min}$ at $72{ }^{\circ} \mathrm{C}$ and a final extension of $7 \mathrm{~min}$ at $72{ }^{\circ} \mathrm{C}$.

The PCR products were purified using EXOI-SAP $(1: 1)$. Sequences were obtained using BigDye terminator (version 3.1) (Applied Biosystems) according to the manufacturer's recommendations and the primers used for PCR; the sequences were analyzed on an Applied Biosystems 3100 genetic analyzer. Electropherograms were checked by eye in ChromasLite (www.technelysium.com.au). The alignments were adjusted by eye in Bioedit v.5.06 software (Hall, 2001). A Bayesian approach run with the program PHASE (Stephens et al., 2001) was used to identify haplotypes of heterozygotes in the nuclear intron; this program reconstructs the haplotype as implemented in DNAsp v. 5.10.01 software (Librado and Rozas, 2009). The RDP (Recombination Detection Program) v.3 (Martin et al., 2005) was used to detect recombination in the set of aligned DNA sequences, based on the following methods: the original RDP, bootscanning, GENECONV, Maximum Chi Square, Chimaera, Sister Scanning and 3SEQ. All of these non-parametric recombination detection methods provided a detailed breakdown of the recombination breakpoint locations and of the identities of recombinant and parental sequences.

\section{Comparison of mtDNA versus $n D N A$ diversity}

For intraspecific analyses, a fragment of $c y t b$ (312 bp) was sequenced in 83 individuals from the Brazilian coast, seven individuals from the Antarctic Peninsula, and five individuals from Marion Island. These sequences were compared with those available in GenBank from New Zealand (NC006007, AY293619 and AF268497) and Kerguelen Island (AF444259). The coding region of ATPase 6 and 8 was sequenced for $58 \mathrm{~L}$. dominicanus individuals from the Brazilian coast. Intron 7 of the $\beta$-fibrinogen gene (858 bp) was sequenced in 66 individuals from the Brazilian coast, seven individuals from the Antarctic Peninsula and three individuals from Marion Island.

Descriptive analyses including haplotype diversity (h), nucleotide diversity $(\pi)$ and Theta per gene $(\theta)$ were calculated for all loci using DNAsp v.5.10.01 (Librado and Rozas, 2009). Tajima's D value (Tajima, 1989) and Fu and Li's $\mathrm{D}^{*}$ and $\mathrm{F}^{*}$ values $(\mathrm{Fu}$ and $\mathrm{Li}, 1993)$ and the significance of these neutrality test statistics were calculated using DNAsp v.5.10.01 (Librado and Rozas, 2009). DNAsp v.5.10.01 was also used to calculate parameters for the demographic history of the population based on mismatch distributions; unimodal curves are expected in populations 
that have undergone rapid population expansion (Rogers and Harpending, 1992). The Raggedness statistic and Ramos-Onsins and Rozas $\mathrm{R}^{2}$ statistics (Ramos-Onsins and Rozas, 2002) were used to test for deviations between the observed and expected on mismatch distribution. Haplotype networks were constructed using the median-joining method (MJN) (Bandelt et al., 1999) as implemented in the NETWORK v.4.1.0.8 software

We used coalescent simulations to generate the predicted levels of genetic diversity based on a priori specified demography history, thus allowing us to contrast nuclear and mitochondrial markers based on the following assumptions or hypothesis: 1) If a demographic event affected the gull populations it would leave signatures in the entire mitochondrial and nuclear genomes; on the other hand, selective events would leave signatures only at individual loci and unlinked loci, 2) Liebers et al. (2001) stated that the last glaciation affected the distribution of these gulls; consequently, if the last glaciation reduced the population size then the ecological expansion observed today is a consequence of expansion after this period, and 3) if this species has a recent origin, as described for other seabirds (Crochet et al., 2003; Pons et al. (2005), then the diversity observed in mitochondrial DNA and nuclear DNA is the result of ancestral polymorphism, with or without expansion of the species.

The simulations based on these three scenarios were run in SIMCOAL2 (Laval and Excoffier, 2004): Scenario 1 - the L. dominicanus population has experienced continuous expansion from the time of its divergence from other Larus species to the present, Scenario 2 - the population passed through a bottleneck that reduced $90 \%$ its original population size 10,000 years ago followed by subsequent expansion and Scenario 3 - the population has a recent origin with regard to the time of divergence from Larus fuscus complex to form L. dominicanus as estimated here and has not experienced expansion or a bottleneck. This approach allowed us to compare the results for all Brazilian populations with simulated data generated under each model, with the following additional assumptions: a substitution rate of $2 \% /$ Myr for cytochrome $b$ (Shields and Wilson, 1986) and $0.53 \% /$ Myr for $\beta$-fibrinogen (Johnson and Clayton, 2000). The initial population sizes were calculated for each population on the Brazilian coast based on the variability of the $\beta$-fibrinogen locus (Table 1). The generation time used in this simulation for L. dominicanus was 10 years based on that estimated for L. michaelis from field data (Crochet et al., 2003). The estimated divergence time between $L$. dominicanus and the L. fuscus complex in this work was used to calculate the number of generations from the divergence up to the present day. For each scenario, 10,000 simulations were run and the SIMCOAL2 results were then analyzed using ARLEQUIN v.3.01 (Excoffier et al., 1992) to estimate Tajima's D values for each simulation. The values obtained during each run were used to construct the distribution of Tajima's D values for each L. dominicanus population on the Brazilian coast. Finally, the observed Tajima's D values for each Brazilian population were compared with the distribution generated by the simulations.

\section{Population analysis}

Population analyses were done only for intron 7 of $\beta$-fibrinogen since the mitochondrial locus showed insufficient variation. Each island was considered as a single population. We estimated the haplotype diversity $(\mathrm{h})$, nucleotide diversity $(\pi)$ and Theta $(\theta)$ per gene for each population using DNAsp v. 5.10.01. In addition, Tajima's D value, Fu and Li's D* and F* values and Ramos-Onsins and Rozas $\mathrm{R}^{2}$ statistics were calculated for all populations and the signifi-

Table 1 - Analysis of the genetic diversity of intron 7 of $\beta$-fibrinogen in various $L$. dominicanus populations, showing the number of polymorphic sites $(\mathrm{S})$, haplotype number $(\mathrm{NH})$, haplotype diversity $(\mathrm{H})$, nucleotide diversity $(\pi)$ and theta $(\theta)$ per gene. The parameters used in the neutrality test of intron 7 of the $\beta$-fibrinogen gene are also shown.

\begin{tabular}{|c|c|c|c|c|c|c|c|c|c|c|}
\hline Localities & & $\mathrm{N}$ & $\mathrm{S}$ & $\mathrm{NH}$ & $\mathrm{H}$ & $\pi$ & $\Theta$ & Tajima's D & Fu and Li's D* & Fu and Li's F* \\
\hline Guararitama & SP & 36 & 18 & 23 & 0.933 & 0.00528 & 3.973 & 0.205 & 0.545 & 0.512 \\
\hline Queimadinha & SP & 24 & 11 & 16 & 0.960 & 0.00442 & 3.181 & 0.287 & 0.355 & 0.384 \\
\hline Laje Conceição & SP & 10 & 9 & 7 & 0.933 & 0.00433 & 3.181 & 1.488 & 0.904 & 1.197 \\
\hline Moleques & SC & 20 & 16 & 13 & 0.905 & 0.00428 & 4.408 & -0.511 & $1.518^{* *}$ & 1.055 \\
\hline Tambores & SC & 12 & 4 & 5 & 0.667 & 0.00150 & 1.325 & -0.016 & 1.195 & 1.004 \\
\hline Deserta & SC & 22 & 13 & 15 & 0.905 & 0.00526 & 3.566 & 1.256 & 1.038 & 1.282 \\
\hline Lobos & SC & 14 & 13 & 10 & 0.945 & 0.00563 & 4.088 & 0.900 & 1.102 & 1.998 \\
\hline Antarctica & IA & 14 & 6 & 4 & 0.571 & 0.00232 & 1.887 & 0.699 & 0.505 & 0.634 \\
\hline Marion & IA & 6 & 0 & 1 & 0 & 0 & 0 & 0 & 0 & 0 \\
\hline Total & & 152 & 33 & 66 & 0.906 & 0.00478 & 5.895 & -0.628 & 0.840 & 0.297 \\
\hline
\end{tabular}

$\mathrm{N}$ - number of individuals. SP - islands in São Paulo state, Brazil; SC - islands in Santa Catarina state, Brazil; IA - islands in the Antarctic region. $* * \mathrm{p}<0.02$. 
cance of these test statistics was assessed using DNAsp v. 5.10.01 (Librado and Rozas, 2009).

The overall differentiation of intron 7 of $\beta$-fibrinogen among the sampled populations was quantified using pairwise F-statistics. Empirical $\mathrm{F}_{\mathrm{ST}}$ values were compared with a null distribution of no difference between the populations to test for significance. The analyses were implemented in ARLEQUIN with 10,000 permutations. Molecular distances were estimated by the method of Tamura (1992) which allows for unequal nucleotide frequencies. The transition-to-transversion ratios, as well as the overall nucleotide frequencies, were computed from the original data. The partitioning of genetic differences among populations was assessed using hierarchical analysis of molecular variance (AMOVA; Excoffier et al., 1992), with 10,000 permutations and estimates of molecular distance (Tamura, 1992).

The Mantel test was used to assess the association between geographic distance and genetic distance for all population pairs. The test was initially included all islands (Brazilian and sub-Antarctic ones) and was then run by considering the Brazilian islands and the Antarctic Peninsula without Marion Island since the latter locality had only one haplotype.

Bayesian Skyline plots were constructed with BEAST v. 1.4.6 (Drummond and Rambaut, 2007) to estimate historical changes in population size over time. Since this method for estimating historical demography assumes that sequences are sampled from a single panmitic population the analysis considered all of the populations as a single group. This method uses Markov-Chain Monte Carlo sampling techniques to estimate the posterior distribution of effective population size given a set of aligned DNA sequences and a model of molecular evolution and takes into consideration uncertainty in the genealogical process (Drummond et al., 2005). The best-fit model of molecular evolution selected based on the criteria of Posada and Cradall (1998) was implemented in PAUP v.4.0 (Swofford, 2000). The skyline plot was run for $20,000,000$ steps with parameters logged every 2,000 steps and a burn-in of $1,000,000$ trees, under a strict molecular clock based on a substitution rate of $0.53 \% / \mathrm{Myr}$ for $\beta$-fibrinogen of $G$. gallus (Jonhson and Clayton, 2000). Skyline plots were constructed using TRACER v.1.4.1 (Drummond and Rambaut, 2007).

\section{Results}

\section{Phylogenetic analyses}

Phylogenetic Bayesian analysis based on cytochrome $b$ was done using the HKY $+\mathrm{G}$ model. The inferred topology showed short branch lengths within gull species (Figure 2). Larus dominicanus appeared as a monophyletic clade and the sister clade consisted of six species from the fuscus complex: L. taymyrensis, $L$. glaucoides, $L$. glaucescens, L. smithsonianns, L. marinus and L. shiasagus

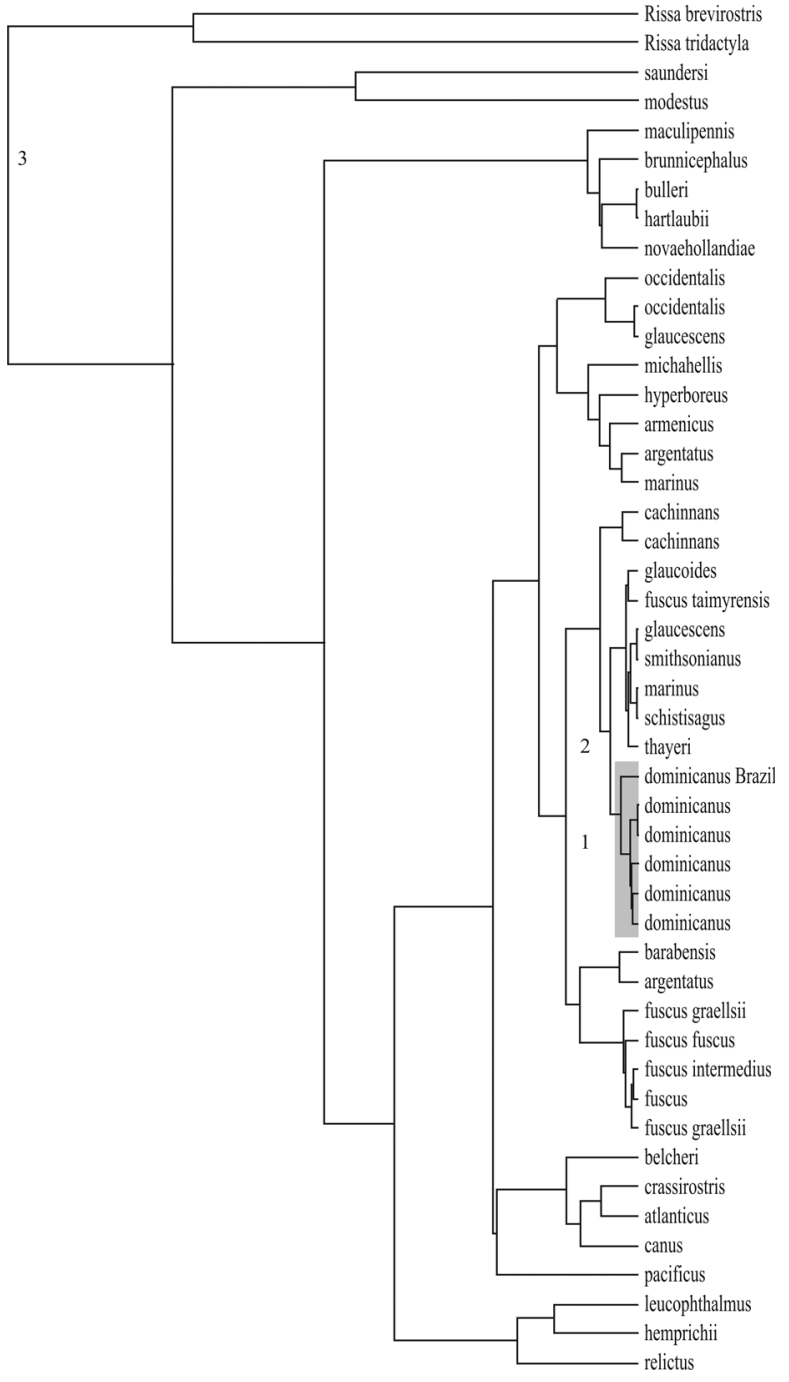

Figure 2 - Bayesian tree based on mtDNA (a fragment of cytochrome b) depicting the phylogenetic relationships of gull species. The numbers indicate the date of the corresponding clade $(1=153,184$ years ago, $2=241,202$ years ago, $3=3,300,00$ years ago) and the light grey shading indicates the dominicanus clade.

(Figure 2). The estimated divergence time of $L$. dominicanus from the fuscus complex was $\sim 241,200$ years ago. The time to the most recent common ancestor of $L$. dominicanus was $\sim 153,184$ years ago.

\section{Intraspecific analyses}

\section{Comparison of mtDNA and nDNA diversity}

Larus dominicanus from the Brazilian coast showed only one haplotype for cytochrome $b$ while the sequences from the Antarctic Peninsula, Marion Island, Kerguelen Island and New Zealand represented another haplotype that differed by a single substitution (Table 2). The coding region of ATPase 6 and 8 contained three haplotypes with two polymorphic sites (Table 2). The most common haplotype found on the Brazilian coast (HBRA01) was identical to the sequences found in New Zealand (NC006007, AY293619) (Figure 3). On the other hand, intron 7 of 


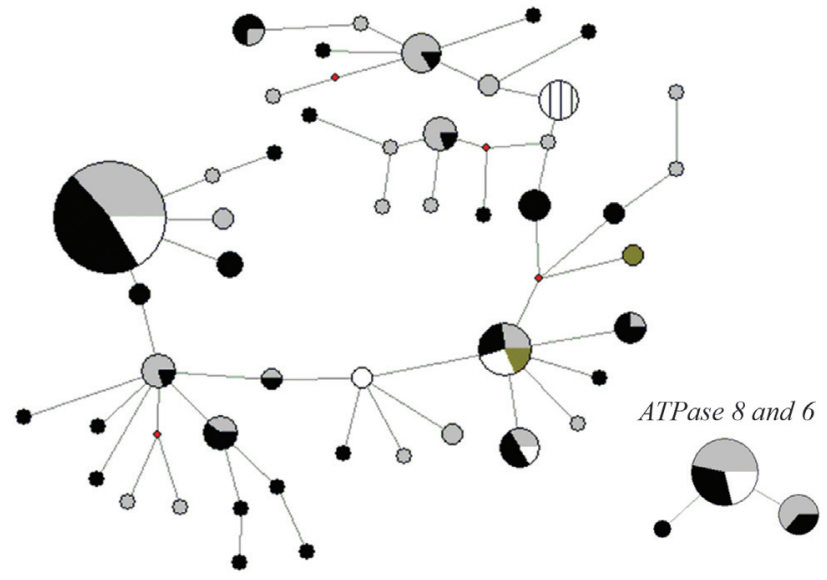

Figure 3 - Median joining networks based on ATPase 6 and 8 mtDNA and intron 7 of $\beta$-fibrinogen (Fib7) nuclear DNA from $L$. dominicanus in the Southern Hemisphere. São Paulo (grey), Santa Catarina (black), Antarctic (white), Marion Island (vertical lines) and outgroup (green).

$\beta$-fibrinogen had a comparatively higher genetic diversity with 55 haplotypes, 28 polymorphic sites, three singletons and 25 parsimonius sites (Figure 3 and Table 2). All of these sequences are available through GenBank accession numbers FJ668863-FJ668936. None of the methods implemented in RDP3 software provided any evidence of recombination in intron 7 of $\beta$-fibrinogen, a finding that allowed the use of all haplotypes in subsequent analyses.

Tajima's D value and Fu and Li's D* and F* values for cytochrome b, ATPase 6 and 8 and intron 7 of $\beta$-fibrinogen revealed no significant deviation from neutrality and the expected equilibrium (Table 2), except for Fu and Li's $D^{*}$ value for intron 7 of $\beta$-fibrinogen. The mismatch distribution of intron 7 of $\beta$-fibrinogen showed a wave signal (multiple peaks) consistent with a stable population (Raggedness index $=0.0110$ and Ramos-Onsins and Rozas $\mathrm{r}^{2}=0.0723, \mathrm{p}=0.60$; intial theta $=1.89$ and tau $=2.19$ ) (Figure 4). However, the mismatch distribution for loci from mtDNA did not show the expected bias for cytochrome $b$ (Raggedness statistic $\mathrm{r}=0.280$ and Ramos-Onsins and Rozas $\mathrm{r}^{2}=0.1367$; estimated initial theta $=0.00$ and tau $=0.273$ ) and ATPase 6 and 8 (Raggedness statistic $\mathrm{r}=0.199$ and Ramos-Onsins and Rozas $\mathrm{r}^{2}=0.0925$; estimated initial theta $=0.000$ and tau $=0.370$ ).

The best scenario from simulations that could explain the variation found in nuclear intron 7 of $\beta$-fibrinogen was the hypothesis of a recent origin and neutral evolution, without marked expansion. None of the models used in the simulations were compatible with the diversity found at the cytochrome $b$ locus. We therefore chose to show only the outcomes of the simulations for this scenario (Figure 5) because other simulations showed distributions that did not include the values observed in the populations.

Population analysis

When Tajima's D value and Fu and Li's D* and F* values for intron 7 of $\beta$-fibrinogen were analyzed for each 


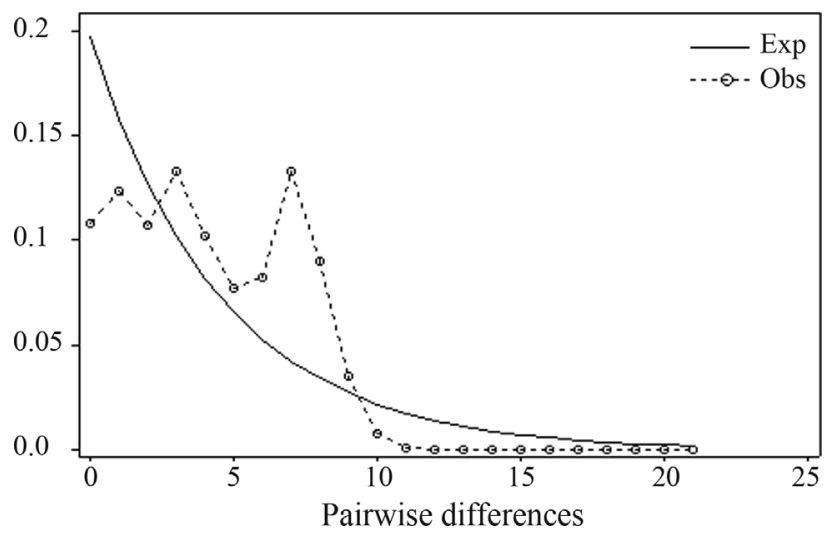

Figure 4 - Mismatch distribution of the fragment of intron 7 of $\beta$-fibrinogen nuclear DNA from $L$. dominicanus in the Southern Hemisphere. Exp - expected, Obs - observed.

population separately they revealed no significant deviation from neutrality and the expected equilibrium, except for the Moleques population in Santa Catarina that deviated significantly from Fu and Li's D test (Table 1).

AMOVA of intron 7 of the $\beta$-fibrinogen revealed significant differentiation among populations, but a large part of the total variation was found within the population $(92 \%$; Table 3). The Marion Island population was the most differentiated population of $L$. dominicanus because of a single exclusive haplotype (Table 4). There was also differentiation between the Antarctic and São Paulo islands
(Guararitama, Queimadinha, Laje da Conceição) but there was no marked differentiation between Santa Catarina islands (Moleques, Tambores, Itacolomis) and the Antarctic. This weak structure was corroborated by the locus network (Figure 3) which detected no exclusive haplotypes for any region, except for Marion Island.

The Mantel test detected a correlation between distance and genetic differentiation when all populations were used in the test $(\mathrm{r}=0.826)$ but this was not significant (test $t=2.5752 ; \mathrm{p}=0.9950)$. The correlation found using that the Mantel test without Marion Island was $r=0.324$ (test $t=1.2651 ; \mathrm{p}=0.8971)$. The Bayesian Skyline analysis indicated rapid growth that started $\sim 10,000$ years ago and has continued up to the present time, with no sign of retraction during the evolutionary history of these lineages of intron 7 of the $\beta$-fibrinogen gene (Figure 6).

\section{Discussion}

\section{Phylogenetic analysis}

The phylogenetic analysis indicated that the Larus group has a recent origin: L. dominicanus diverged from the fuscus complex 241,201 years ago and the time to the most recent common ancestor was estimated at 153,184 years ago (Figure 2). Other researchers have also shown that the Larus group has a recent origin. The argentatus-fuscus complex diverged between 100,000 and 170,000 years ago (Crochet and Desmarais, 2000); the species into this com-

Table 3 - Analysis of molecular variance (AMOVA) for intron 7 of the $\beta$-fibrinogen gene of $L$. dominicanus populations.

\begin{tabular}{lccc}
\hline Source of variation & Degrees of freedom & Sum of squares & Variance components \\
\hline Among population & 8 & 7.903 & $0.03565 \mathrm{Va}$ \\
Within population & 139 & 58.374 & $0.41996 \mathrm{Vb}$ \\
Total & 147 & 66.277 & 0.45560 \\
\hline
\end{tabular}

Fst $=0.074, p=0.00$. Va: covariance component due to differences among populations within populations. Vb: covariance component among individuals within populations.

Table 4 - Pairwise $\mathrm{F}_{\mathrm{ST}}$ values for intron 7 of $\beta$-fibrinogen (below diagonal) among populations of $L$. dominicanus. Significant values (p $<0.05$ ) are indicated in bold.

\begin{tabular}{|c|c|c|c|c|c|c|c|c|c|}
\hline & Laje & Gua & Quei & Mole & Tam & Des & Lob & Ant & Marion \\
\hline Laje & - & & & & & & & & \\
\hline Gua & -0.225 & - & & & & & & & \\
\hline Quei & -0.119 & 0.000 & - & & & & & & \\
\hline Mole & 0.025 & 0.038 & 0.112 & - & & & & & \\
\hline Des & -0.009 & -0.011 & 0.191 & 0.037 & -0.004 & - & & & \\
\hline Lob & 0.161 & 0.120 & 0.270 & 0.033 & 0.107 & 0.147 & - & & \\
\hline Ant & 0.114 & 0.088 & 0.242 & 0.003 & 0.066 & 0.067 & 0.082 & - & \\
\hline Marion & 0.539 & 0.407 & 0.434 & 0.625 & 0.548 & 0.424 & 0.844 & 0.780 & - \\
\hline
\end{tabular}



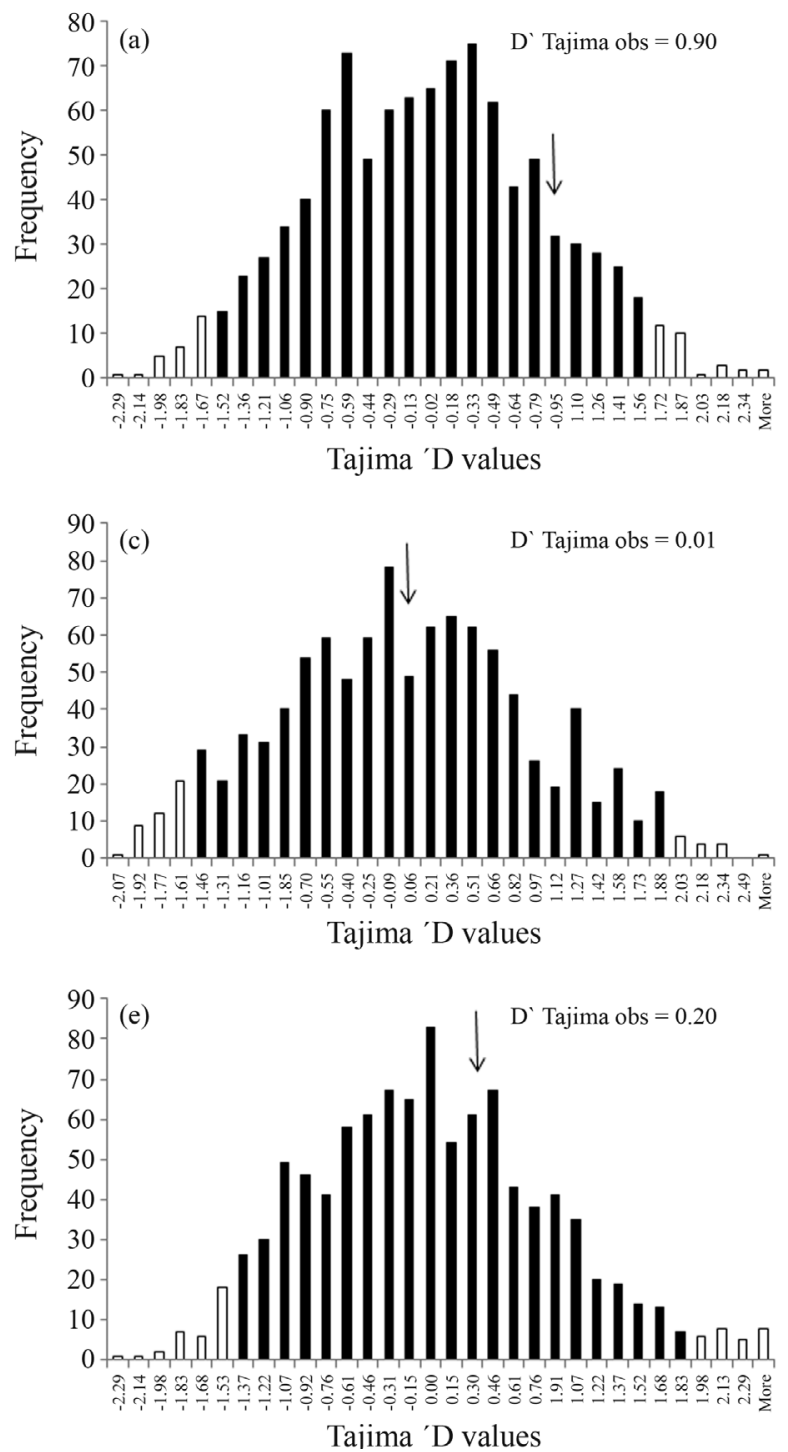
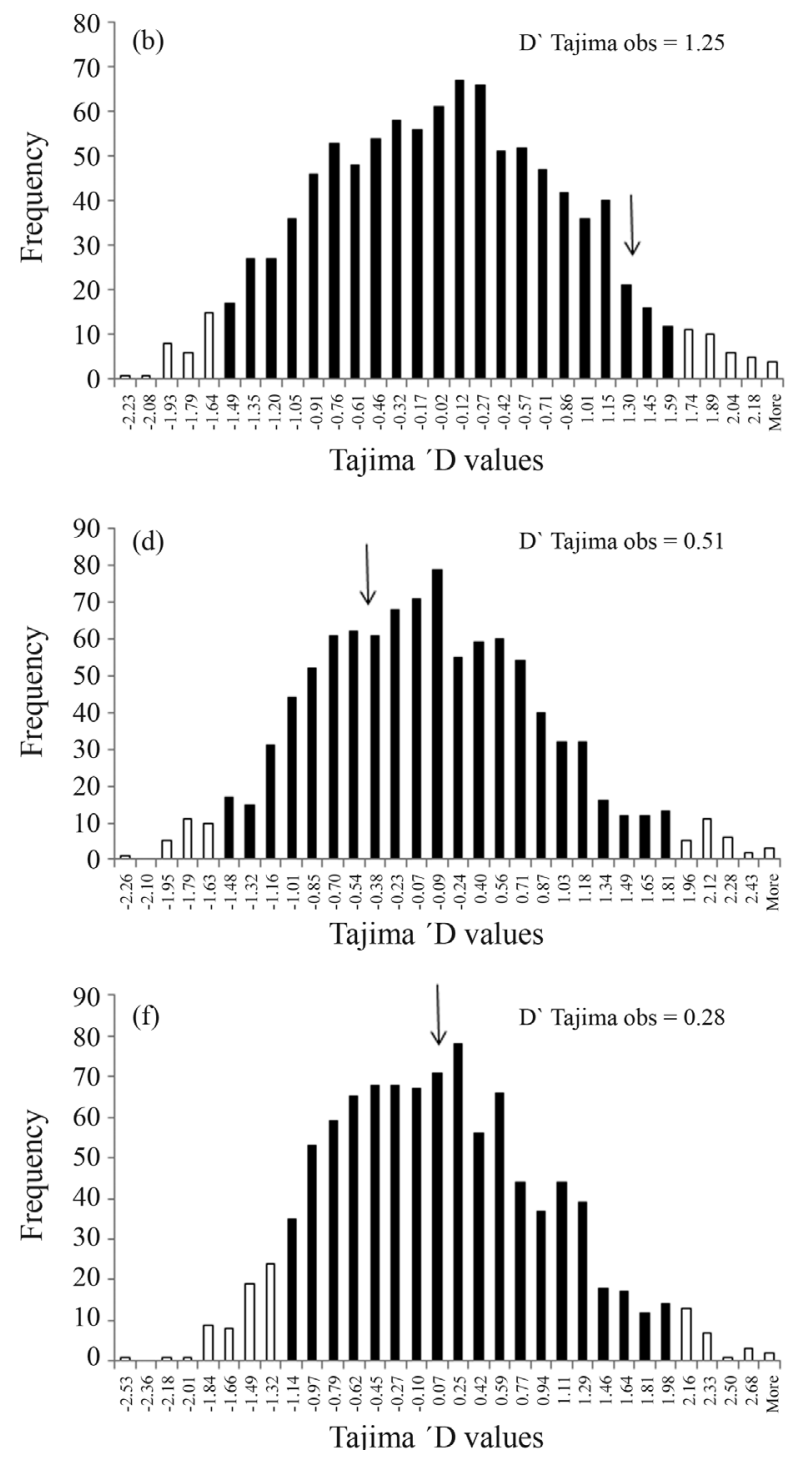

Figure 5 - Histogram of the simulation for intron 7 of $\beta$-fibrinogen from $L$. dominicanus populations along the Brazilian coast. Recent origin scenario: (a) Lobos Island - RS, (b) Deserta Island - SC, (c) Tambores Island - SC, (d) Moleques do Sul Island - SC, (e) Queimadinha Island - SP and (f) Guararitama Island - SP. The arrows indicate the position of our data in the histogram.

plex share several haplotypes and hybridization is observed in their contact zone in the Northern Hemisphere. Given et al. (2005) also reported a recent origin for masked gulls since they estimated that nine species in the Southern Hemisphere diverged from a common ancestor $\sim 0.5$ Mya. Overall, there is a consensus regarding the recent divergence of the genus Larus and the cause of extensive hybridization among species in the Northern Hemisphere (Liebers et al., 2001, 2004; Crochet et al., 2003; Given et al., 2005).

\section{Comparison of mtDNA and nDNA diversity}

The mtDNA results for Kelp Gulls were lower than those found in another groups of birds in which the same cytochrome $b$ region was analyzed. Brooke and Rowe (1996) reported a haplotype diversity of 0.68 and nucleotide diversity of 0.0013 for Pterodroma magenta whereas the corresponding values for Brichyranphys perdix were 0.70 and 0.004, respectively (Friesen et al., 1996). Proudfoot et al. (2006) observed a nucleotide diversity of 0.013 for Glaucidium brasilianum and Mundy et al. (1997) reported a corresponding value of 0.0043 for Lanius ludovicianus. All of these indicators of diversity in seabirds or other groups were considerably higher than in Kelp Gulls, for which the haplotype diversity was 0.273 and the nucleotide diversity 0.00083 . On the other hand, the haplotype diversity (0.89) of intron 7 of $\beta$-fibrinogen was similar to that of seabirds such as Calidris pussilla on the northern coast of Brazil (Gonçalves et al., 2007).

The low genetic diversity observed for cytochrome $b$ and ATPase 8 and 6 was compatible with both demographic and selective processes. Demographic factors include bottlenecks and founder effects, both of which reduce popula- 


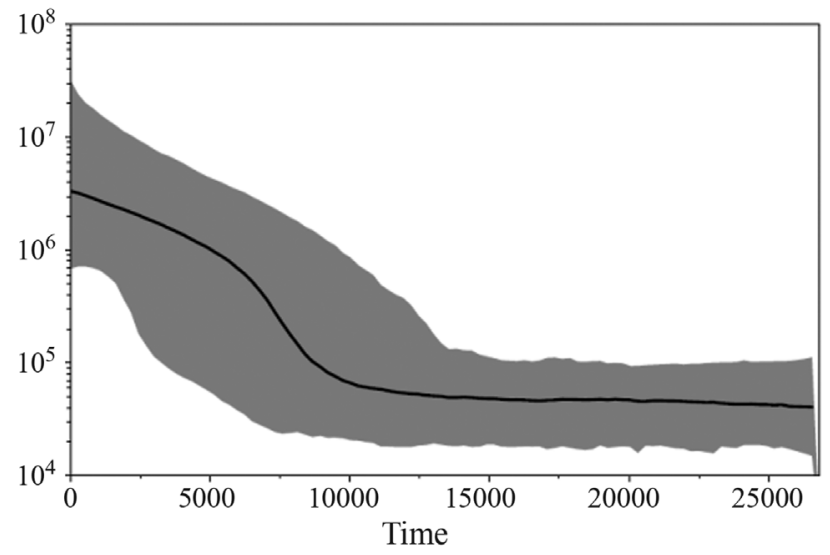

Figure 6 - Bayesian skyline plot for intron 7 sequences of $\beta$-fibrinogen with a log-normal restricted clock and a generation time of 10 years. The $y$-axis shows the effective number of individuals. The thick solid line is the estimated median and the gray shaded area shows the $95 \%$ highest density limits. The $\mathrm{x}$-axis is scaled as thousand years ago (Ya).

tion size temporally and result in an increased rate of genetic drift (Galtier et al., 2000). On the other hand, the rapid fixation of a new, favorable allele through directional selection (selective sweep) can also reduce genetic variability at a locus under selection and at linked loci (Galtier et al., 2000). A reduction in genetic variability can transform an abundant species into a species with a high probability of extinction because of stochastic events such as infection by new pathogens. Nevertheless, the $\beta$-fibrinogen gene showed high diversity, indicating that the genetic variability of Kelp Gulls is not at a critical level (Table 2).

The low genetic variability at mtDNA loci and a comparatively higher level of variation at intron 7 of $\beta$-fibrinogen allowed us to formulate three hypotheses: Hypothesis 1 - demographic events reduced the genetic diversity of both mitochondrial and nuclear genes, but the difference in effective size between these molecules preserved greater diversity at the nuclear gene, Hypothesis 2 - the recent demographic expansion of $L$. dominicanus can explain the low genetic diversity in mtDNA while the high diversity in intron 7 of $\beta$-fibrinogen reflects ancestral polymorphism; these findings reflect differences in the effective population size for these markers and the divergence time of the species, and Hypothesis 3 - mitochondrial DNA from L. dominicanus experienced a selective sweep that reduced its variability.

Hypothesis 1 could be the outcome of founder events or bottleneck events on the Brazilian coast. Recent colonization can lead to reduced genetic diversity since all individuals are descendants of a small founder group (Hartl and Clarck, 1989). If populations on the Brazilian coast are the result of recent colonization then this may have involved specimens from the Pacific coast of South America, the southeast Atlantic Ocean, South Africa or Australia. Regardless of the origin of these populations, this species would use the sub-Antarctic islands and Antarctic Penin- sula as a route to migrate to the Brazilian coast. Considering this route of migration, the colonies on the Atlantic coast of South America would be expected to show differentiation in a south-north direction. However, as shown here, there was low genetic differentiation in mitochondrial markers such as cytochrome $b$ when compared with populations from Australia, New Zealand and Kerguelen Island. Overall, the low genetic variability of the Brazilian populations compared with other colonies in the Southern Hemisphere was not consistent with the hypothesis that the colonization of this region involved founder events. On the other hand, intron 7 of $\beta$-fibrinogen showed a cline of differentiation between the Antarctic and Brazilian coast (Table 4), indicating that this hypothesis cannot be discarded; however, its acceptance would require an analysis of samples from the Pacific and other sub-Antarctic islands.

A second possible demographic event that may have occurred in L. dominicanus is the loss of genetic diversity as a result of bottlenecks in the last glaciations. Pleistocene glaciers promoted changes in sea temperature, currents and other physiochemical characteristics that may have affected the population history of tropical birds (Peck and Congdon, 2004). Glacial cycles in the Pleistocene that were associated with ecological changes affected the dynamics of gull populations in the Northern Hemisphere (Liebers et al., 2001). Oscillations in sea levels and changes in ecological factors in response to glacial cycles may have reduced the size of the Kelp Gull population. This reduction may have led to the loss of genetic variability through successive reduction and expansion of the population. Sea levels are known to have oscillated during the Quaternary glaciations (Bigarela, 1965). On the Brazilian coast, the sea level was up to 10 meters above its current level (Suguio, 2004) and there is evidence that regressions of approximately 100 meters below the current level occurred in the Pleistocene (Bigarela, 1965). Such fluctuations may have altered the breeding sites for this species. However, the influence of sea level fluctuations on the genetic diversity of seabirds with a wide distribution and high capacity for dispersion remains unclear.

As shown here, Tajima's D value and Fu and Li's D* and $\mathrm{F}^{*}$ values and the R2 neutrality tests for intron 7 of $\beta$-fibrinogen showed no signs of the population expansion that would be expected in the case of a recent bottleneck followed by expansion. Fu and Li's D* and F* values and the $\mathrm{R}^{2}$ statistic are more sensitive indicators of range expansion when compared to Tajima's D value (Ramos-Onsins and Rozas, 2002). $\mathrm{R}^{2}$ is more effective when testing small sample sizes, but these tests did not detect any sign of expansion in Kelp Gull. These results were corroborated by mismatch distribution that showed no sign of population expansion, with a multimodal distribution consistent with a population in demographic equilibrium (Excoffier et al., 1992). However, ecological data suggest that Kelp Gulls have increased at a rate of $50 \%$ per year (Dantas and 
Morgante, 2010) and the Bayesian Skyline plot clearly showed the expansion of $L$. dominicanus from 10,000 years ago up to the present-day, but no sign of bottleneck events (Figure 6). The conditions that prevailed after the last glaciations probably favored the expansion of $L$. dominicanus on the Brazilian coast. Although the summary statistics of the data for intron 7 of $\beta$-fibrinogen were consistent with a population in equilibrium, the ecological data and Bayesian analysis indicated expansion of the population. Gonçalves et al. (2007) also observed marked genetic diversity in C. pusilla on the northern coast of Brazil based on an analysis of intron 7 of $\beta$-fibrinogen; these authors suggested that this diversity was the result of recent growth in population size and that the populations had not experienced recent bottleneck events.

Based on a generation time of 10 years for Kelp Gulls and their recent origin dated at 241,201 years ago (which correspond to 24,120 generations) it seems reasonable to question whether this length of time is compatible with the absence of variation in the mtDNA locus but insufficient for splitting of the nuclear genome. The simulations showed that divergence time did not explain the low genetic variability observed in mtDNA whereas a recent origin explained the genetic diversity seen in $\beta$-fibrinogen (Figure 5). This simple demographic scenario therefore cannot explain the low genetic diversity in mtDNA and the hypothesis of a selective sweep in mtDNA cannot be discarded. In addition, Bazin et al. (2006) have shown that natural selection acting on mtDNA contributes to the homogenization of diversity. These authors affirmed that mtDNA frequently undergoes adaptive evolution involving direct selection that targets the respiratory machinery, i.e., a form of nucleo-cytoplasmic coadaptation. An investigation of other mtDNA markers is needed to confirm this hypothesis.

\section{Population diversity}

Intron 7 of the $\beta$-fibrinogen gene of the Kelp Gull showed similar variation that found in other Charadriiform seabirds. Gonçalves et al. (2007) reported a nucleotide diversity of 0.0048 and haplotype diversity of 0.97 for this species whereas we estimated the corresponding values to be 0.0046 and 0.89 , respectively. Our results were consistent with previous genetic studies of seabirds on the Brazilian coast (Gonçalves et al., 2007; Faria et al., 2010) in that we observed a low genetic population structure among Kelp Gull populations $\left(\mathrm{F}_{\mathrm{ST}}=0.074\right)$ and little differentiation when compared with sub-Antarctic islands (Marion and King George) (Table 4). This outcome was corroborated by network analysis that showed identified shared haplotypes among regions, and by the Mantel test that detected no significant correlation between geographic distance and genetic diversity.

The low genetic structure in the Kelp Gull could reflect the current high levels of dispersal since this species can fly hundreds of kilometers on foraging trips and the
Brazilian coast has no apparent barriers to seabird dispersal. Marine currents are believed to play an important role in species distribution and dispersion. The Brazilian coast is influenced by a warm, nutrient-poor current that flows from north to south. In contrast, the Falklands current is cold, rich in nutrients and flows from the south up to Rio de Janeiro in the north. Consequently, all of the Kelp Gull colonies examined were influenced by the same currents. The Kelp Gull is a poorly studied species for which important ecological data and information on the migratory routes are still lacking. To understand the population dynamics of this species it will be necessary to gather ecological and demographic information throughout the species' distribution.

One important result of this study was that the Bayesian skyline plot detected signs of a change in population size, with a clear expansion after the last glacial maximum and no retraction during the glacial period. This outcome is consistent with the population expansion detected based on ecological data from several sites around the world (Quintana and Yorio, 1998; Steele and Hockey, 1990).

\section{Conclusions}

L. dominicanus has shown population growth in recent decades, with skyline plots showing a rapid increase during the last 10,000 years. Neutrality tests based on summary statistics showed no deviation from a neutral equilibrium model and there was no sign of bottleneck events. A simple demographic scenario based on the estimated time of divergence between $L$. fuscus and $L$. dominicanus did not explain the low genetic diversity found in mtDNA. In addition, the genetic diversity found in the nuclear gene agreed with the expected neutrality, especially considering that the divergence between the $L$. fuscus complex and $L$. dominicanus occurred 241,201 years ago. Based on these findings, we cannot discard a selective sweep hypothesis for mtDNA, although a recent origin followed by rapid expansion of this species after the last glacial period is the most likely scenario.

\section{Acknowledgments}

This work was supported by Fundação de Amparo a Pesquisa de São Paulo (FAPESP, grant no. 05/55438-4). Gisele Dantas was supported by a FAPESP PhD scholarship (grant no. 03/01599-1). We thank the Instituto Florestal de São Paulo, Estação Ecológica Juréia-Itatins for logistical support (783/2003) and CEMAVE/ICMBio for providing metal bands and permits (licence no. 1060). We thank friends and colleagues who helped with the field work and Joaquim O. Branco, Fausto Campos, Peter Ryan and Martin Sander for help with sampling. We are especially grateful to M.A. Aires, J.O. Branco, C.Y. Miyiaki and M.C. Arias for their suggestions on previous drafts. 


\section{References}

Austin JJ, Whoite RWG and Ovenden JR (1994) Populationgenetic structure of phylopatric colonially nesting seabirds, the Short-tailed Shearwater (Puffinus tenuirostris). Auk 11:70-79.

Avise JC, Nelson WS, Bowen BW and Walker D (2000) Phylogeography of colonially nesting seabirds, with special reference to global matrilineal patterns in the Sooty tern (Sterna fuscata). Mol Ecol 9:1783-1892.

Ballard JWO and Whitlock MC (2004) The incomplete natural history of mitochondria. Mol Ecol 13:729-744.

Bandelt H-J, Forster P and Röhl A (1999) Median-joining networks for inferring intraspecific phylogenies. Mol Biol Evol $16: 37-48$

Bazin E, Glemin S and Galtier N (2006) Population size does not influence mitochondrial genetic diversity in animals. Science 312:570-572.

Bigarela JJ (1965) Subsídios para estudos da variação do nível oceânico no Quarternário brasileiro. Ann Acad Bras Ciênc 37:263-278.

Bridge ES, Jones AW and Baker AJ (2005) A phylogenetic framework for the terns (Sternini) inferred from mtDNA sequences: Implications for taxonomy and plumage evolution. Mol Phylogenet Evol 35:459-469.

Brooke MDL and Rowe G (1996) Behavioural and molecular evidence for specific status of light and dark morphs of the Herald Petrel Pterodroma heraldica. Ibis 138:420-432.

Brown LM, Ramey IIRR, Tamburini B and Gavin TA (2004) Population structure and mitochondrial DNA variation in sedentary Neotropical birds isolated by forest fragmentation. Conserv Genet 5:743-755.

Burger J and Gochfeld M (1996) Laridae. In: del Hoyo JA and Elliott SJ (eds) Handbook of the Birds of the World. Volume 3. Hoatzin to Auks. Lynx Ediciones, Barcelona, $821 \mathrm{pp}$.

Congdon BC, Piatt HF, Martin K and Friesen VL (2000) Mechanisms of population differentiation in Marbled Murrelets: Historical versus contemporary processes. Evolution 54:974-986.

Crochet PA and Desmarais E (2000) Slow rate of evolution in the mitochondrial control region of gulls (Aves, Laridae). Mol Biol Evol 17:1797-1806.

Crochet PA, Chen JZ, Pons JM, Lebreton JD, Hebert PDN and Bonhomme F (2003) Genetic differentiation at nuclear and mitochondrial loci among Large White-Headed Gulls: Sexbiased interspecific gene flow? Evolution 57:2865-2878.

Dantas GPM and Morgante JS (2010) Breeding biology of Kelp Gull on the Brazilian coast. Wilson J Ornithol 122:39-45.

Desjardin P and Morais R (1990) Sequence and gene organization of the chicken mitochondrial genome: A novel gene order in higher vertebrates. J Mol Biol 212:599-634.

Drummond AJ and Rambaut A (2007) BEAST: Bayesian evolutionary analysis by sampling trees. BMC Evol Biol 7:214.

Drummond AJ, Rambaut A, Shapiro B and Pybus OG (2005) Bayesian coalescent inference of past population dynamics from molecular sequences. Mol Biol Evol 22:1185-1192.

Excoffier L, Smouse PE and Quattro JM (1992) Analysis of molecular variance inferred from metric distances among DNA haplotypes: Application to human mitochondrial DNA restriction data. Genetics 131:479-491.

Faria PJ, Baus E, Morgante JS and Bruford MW (2007) Challenges and prospects of population genetics studies in terns
(Sternidae, Charadriiformes, Aves). Genet Mol Biol 30:681-689.

Faria PJ, Campos FP, Branco JO, Musso CM, Morgante JS and Bruford MW (2010) Population structure in the South American tern Sterna hirundinacea in the South Atlantic: Two populations with distinct breeding phenologies. J Avian Biol 41:378-387.

Friesen VL, Piatt JF and Baker AJ (1996) Evidence from cytochrome b sequences and allozymes for a "new" species of alcid: The Long-billed Murrelet (Brachyramphus perdix). Condor 98:681-690.

Fu Y-X and Li WH (1993) Statistical tests of neutrality of mutations. Genetics 133:693-709.

Galtier N, Depaulis F and Barton NH (2000) Detecting bottlenecks and selective sweep from DNA sequence polymorphism. Genetics 155:981-987.

Genovart ML, Oro D and Bonhomme F (2003) Genetic and morphological differentiation between two largest breeding colonies of Audouin's Gull Larus audouinii. Ibis 145:448-456.

Given AD, Mills JA and Baker AJ (2005) Molecular evidence for recent radiation in southern hemisphere Masked Gull. Auk 122:268-279.

Godinho R, Mendonça B, Crespo EG and Ferrand N (2006) Genealogy of the nuclear $\beta$-fibrinogen locus in a highly structured lizard species: Comparison with mtDNA and evidence for intragenic recombination in the hybrid zone. Heredity 96:454-463.

Gonçalves EC, Rodrigues AAF, Ferrari SF, Silva A and Schneider MPC (2007) Molecular evolution of $\beta$-fibrinogen intron 7 applied to the population genetics of the Semilpalmated Sandpiper (Calidris pusilla) on the northern coast of Brazil. Rev Bras Orn. 15:253-260.

Hall TA (2001) BioEdit: A user-friendly biological sequence alignment editor and analysis program for Windows 95/98/NT. Nucleic Acids Symp Ser 41:95-98.

Hare MP, Cipriano F and Palumbi SR (2002) Genetic evidence on the demography of speciation in allopatric dolphin species. Evolution 56:804-816.

Hartl DL and Clarck AG (1989) Principles of Population Genetics. Sinauer Associates, Sunderland, 682 pp.

Helbig AJ and Seibold J (1999) Molecular phylogeny of Paleartic-African Acrocephalus and Hippolis warblers (Aves, Sylviidae). Mol Phylogenet Evol 11:246-260.

Johnson KP and Clayton DH (2000) Nuclear and mitochondrial genes contain similar phylogenetic signal for pigeons and doves (Aves, Columbiformes). Mol Phylogenet Evol 14:141-151

Laval G and Excoffier L (2004) SIMCOAL ver. 2.0: A program to simulate genomic diversity over larger recombination regions in a subdivided population with a complex history. Bioinformatics 20:2485-2487.

Librado P and Rozas J (2009) DnaSP ver. 5: A software for comprehensive analysis of DNA polymorphism data. Bioinformatics 25:1451-1452.

Liebers D, Helbig AJ and De Kniff P (2001) Genetic differentiation and phylogeography of gulls in the Larus cachinnansfuscus group (Aves, Charadriiformes). Mol Ecol 10:24472462.

Liebers D, Knijff P and Helbig AJ (2004) The herring gull complex is not a ring species. Proc R Soc Lond B 271:893-901. 
Martin DP, Williamson C and Posada D (2005) RDP2: Recombination detection and analysis from sequence alignments. Bioinformatics 21:260-262.

Melo-Ferreira J, Alves PC, Freitas H, Ferrand N and Boursot P (2009) The genomic legacy from the extinct Lepus timidus to the three hare species of Iberia: Contrast between mtDNA, sex chromosomes and autosomes. Mol Ecol 18:2643-2658

Mundy NI, Winchell CS and Woodruff DS (1997) Genetic differences between the endangered San Clemente Island Loggerhead Shrike Lanius ludovvicianus mearnsiani and two neighbouring subspecies demonstrated by mtDNA control region and cytochrome $\mathrm{b}$ sequence variation. Mol Ecol 6:29-37.

Paton TA, Baker AJ, Groth JG and Barrowclough GF (2003) RAG-1 sequences resolve phylogenetic relationships within Charadrii-form birds. Mol Phylogenet Evol 29:268-278.

Peck DR and Congdon BC (2004) Reconciling historical processes and population structure in the Sooty tern Sterna fuscata. J Avian Biol 35:327-335.

Pons JM, Crochet PA, Thery M and Bermejo A (2004) Geographical variation in the Yellow-legged gull: Introgression or convergence from the Herring gull? J Zool Syst Evol Res 42:245-256.

Pons JM, Hassanin A and Crochet PA (2005) Phylogenetic relationships within the Laridae (Charadriiformes, Aves) inferred from mitochondrial markers. Mol Phylogenet Evol 37:686-699.

Posada D and Cradall KA (1998) Modeltest: Testing the model of DNA substitution. Bioinformatics 14:817-818.

Proudfoot GA, Honeycutt RL and Slack DR (2006) Mitochondrial DNA variation and phylogeography of the ferruginous pygmy-owl (Glaucidium brasilianum). Conserv Genet $7: 1-12$.

Prychitko TM and Moore WS (2000) Comparative evolution of the mitochondrial cytochrome $b$ gene and nuclear $\beta$-fibrinogen intron 7 in woodpeckers (Aves, Picidae). Mol Phylogenet Evol 8:193-204.

Quintana F and Yorio P (1998) Competition for nest sites between Kelp Gull (Larus dominicanus) and terns (Sterna maxima and S. eurygnatha) in Patagonia. Auk 115:1068-1071.

Ramos-Onsins SE and Rozas J (2002) Statistical properties of new neutrality tests against population growth. Mol Biol Evol 19:2092-2100.

Rogers AR and Harpending H (1992) Population growth makes waves in the distribution of pairwise genetic differences. Mol Biol Evol 9:552-569.

Rowntree VJ, MacGuinness P, Marshall K, Payne R, Sirone M and Seger J (1998) Increased harassment of Right Whales (Eubalena australis) by Kelp Gull (Larus dominicanus) at Peninsula Váldez, Argentina. Mar Mammal Sci 14:99-115.

Sambrook KJ, Russel DW and Sambrook J (2001) Molecular Cloning: A Laboratory Manual. Cold Spring Harbor Laboratory Press, New York.

Shields GF and Wilson AC (1987) Calibration of mitochondrial evolution in geese. J Mol Evol 24:212-217.
Sorenson MD, Ast JC, Dimcheff DE, Yuri T and Mindell DP (1999) Primers for a PCR-based approach to mitochondrial genome sequencing in birds and other vertebrates. Mol Phylogenet Evol 12:105-114.

Steele WK and Hockey PAR (1990) Population size, distribution and dispersal of Kelp Gulls in the Southwestern Cape, South Africa. Ostrich 61:97-106.

Stephens M, Smith NJ and Donnelly P (2001) A new statistical method for haplotype reconstruction from population data. Am J Hum Genet 73:1162-1169.

Suguio K (2004) O papel das variações do nível relativo do mar durante o Quaternário tardio na origem da baixada litoranea da Juréia, SP. In: Otavio AV and Marques WD (eds) Estação Ecológica Juréia-Itatins: Ambiente Físico, Flora e Fauna. Holos, Ribeirão Preto, pp 33-41.

Swofford DL (2000) PAUP, Phylogenetic analysis using parsimony and other methods. Sinauer Associates, Sunderland, $142 \mathrm{pp}$.

Tajima F (1989) Statistical method for testing the neutral mutation hypothesis by DNA polymorphism. Genetics 123:585-595.

Tamura K (1992) Estimation of the number of nucleotide substitutions when there are strong transition-transversion and $\mathrm{G}+\mathrm{C}$ content biases. Mol Biol Evol 9:678-687.

Thomas PO (1988) Kelp Gulls, Larus dominicanus, are parasites on flesh of the Right Whale, Eubalaena australis. Ethology 79:89-103.

Zhang X and Hewitt GM (2003) Nuclear DNA analyses in genetic studies of populations: Practice, problems and prospects. Mol Ecol 12:563-584.

Zink RM and Barrowclough GF (2008) Mitochondrial DNA under siege in avian phylogeography. Mol Ecol 17:2107-2121.

\section{Internet Resources}

NETWORK ver. 4.1.0.8, http://www.fluxus-engineering.com/sharepub.htm\#a1 (December 26, 2011).

Mantel test, http://life.bio.sunysb.edu/morph/soft-mult.html (December 26, 2011).

\section{Supplementary Material}

The following online material is available for this article:

Table S1 - List of the 105 taxa of the genus Larus used in the phylogenetic analysis. The genus Rissa was used to root the tree. The accession numbers are from GenBank.

This material is available as part of the online article from http://www.scielo.br/gmb.

Associate Editor: Fabricio Santos

License information: This is an open-access article distributed under the terms of the Creative Commons Attribution License, which permits unrestricted use, distribution, and reproduction in any medium, provided the original work is properly cited. 
Table S1 - List of the 105 taxa of the genus Larus used in the phylogenetic analysis. The genus Rissa was used to root the tree.

The accession numbers are from GenBank.

AB208758.1l Larus canus

AB208757.1l Larus canus

AB208756.1l Larus canus

AB208754.1l Larus crassirostris

AB208753.1l Larus crassirostris

EF513630.1l Larus argentatus

EF513629.1। Larus argentatus

EF513628.1| Larus argentatus

EF513627.1। Larus argentatus

EF513626.1l Larus cachinnans

EF513625.1। Larus argentatus

EF513624.1। Larus cachinnan

EF513623.1l Larus cachinnans

EF373138.1l Larus marinus

AY964952.1। Larus hemprichii

AY964949.1। Larus relictus

AY964948.1l Larus saundersi

AY964947.1l Larus maculipennis

AY964946.1। Larus bulleri

AY964945.1। Larus novaehollandiae

AY964944.1I Larus hartlaubii

AY964943.1I Larus brunnicephalus

AY964942.1I Larus armenicus

AY964941.1l Larus cachinnan

AY964940.1l Larus glaucescens

AY964939.1l Larus leucophthalmus

AY964938.1। Larus modestus

AY964937.1। Larus crassirostris

AY964936.1l Larus atlanticus

AY964935.1। Larus belcheri

AY964934.1I Larus pacificus

AY615706.1। Larus thayeri

AY615705.1। Larus thayeri

AY615704.1। Larus thayeri

AY615703.1l Larus glaucescens

AY615702.1l Larus glaucescens

AY615701.1| Larus glaucescens

AY615700.1l Larus glaucescens 
AY615699.1। Larus occidentalis

AY615698.1। Larus occidentalis wymani

AY615697.1l Larus occidentalis wymani

AY615696.1। Larus occidentalis occidentalis

AY615695.1। Larus occidentalis occidentalis

AY615694.1l Larus occidentalis occidentalis

AJ508148.1। Larus schistisagus

AJ508147.1I Larus occidentalis

AJ508145.1। Larus michahellis

AJ508144.1। Larus michahellis

AJ508091.1l Larus argentatus

AJ508092.1I Larus argentatus argenteus

AJ508094.1I Larus argentatus argenteus

AJ508095.1। Larus argentatus argenteus

AJ508096.1I Larus argentatus argenteus

AJ508097.1I Larus argentatus argenteus

AJ508098.1I Larus argentatus argenteus

AJ508099.1I Larus argentatus argenteus

AJ508100.1l Larus argentatus argenteus

AJ508103.1। Larus argentatus smithsonianus

AJ508104.1I Larus argentatus smithsonianus

AJ508122.1l Larus fuscus fuscus

AJ508105.1। Larus argentatus smithsonianus

AJ508106.1। Larus argentatus smithsonianus

AJ508107.1I Larus argentatus smithsonianus

AJ508108.1I Larus argentatus smithsonianus

AJ508109.1। Larus argentatus smithsonianus

AJ508110.1l Larus armenicus

AJ508111.1l Larus cachinnans barabensis

AJ508112.1 Larus cachinnans barabensis

AJ508113.1। Larus cachinnans barabensis

AJ508114.1l Larus cachinnans

AJ508115.1l Larus cachinnans

AJ508116.1। Larus cachinnans

AJ508117.1। Larus cachinnans

AJ508118.1l Larus cachinnans

AJ508119.1l Larus cachinnans

AJ508120.1l Larus cachinnans

AJ508121.1l Larus dominicanus

AJ508143.1l Larus michahellis 
AJ508142.1I Larus michahellis

AJ508141.1I Larus michahellis atlantis

AJ508140.1I Larus marinus

AJ508138.1I Larus hyperboreus

AJ508123.1। Larus fuscus fuscus

AJ508124.1I Larus fuscus fuscus

AJ508125.1l Larus fuscus graellsii

AJ508126.1I Larus fuscus graellsii

AJ508128.1। Larus fuscus graellsii

AJ508129.1। Larus fuscus graellsii

AJ508130.1I Larus fuscus heuglini

AJ508131.1l Larus fuscus intermedius

AJ508139.1l Larus hyperboreus

AJ508136.1I Larus hyperboreus

AJ508135.1l Larus hyperboreus

AJ508137.1I Larus hyperboreus

AJ508134.1| Larus glaucoides

AJ508133.1। Larus glaucoide

AJ508132.1I Larus fuscus taimyrensis

AJ508127.1I Larus fuscus graellsii

Nc006007 | Larus dominicanus

AY293619| Larus dominicanus

AJ508121| Larus dominicanus

AF268497I Larus dominicanus

AF 444259| Larus dominicanus

DQ385229| Rissa tridactyla

AF268523| Rissa brevirostris 